\title{
Factors associated with smoking cessation in South Africa
}

\author{
Olalekan A Ayo-Yusuf, Ben Szymanski
}

Objectives. To determine the factors associated with attempting to quit smoking and successfully doing so, among South Africans.

Methods. Data from the 1998 South African Demographic and Health Survey (the largest nationally representative survey dataset available to date) were used. We compared the characteristics of those who attempted to quit, with those of the entire population of smokers, and compared successful quitters with those who only attempted to quit. The data analysis included logistic regression analysis.

Results. Of those who ever smoked and who smoked $\geq 100$ cigarettes, $68.1 \%$ ( $N=2223)$ attempted to quit smoking, but only $14.1 \%$ succeeded of those who ever attempted to quit. Those who attempted to quit were significantly more likely to be female, white, $\geq 55$ years old, have tertiary education,

Smoking causes an estimated $8 \%$ of all adult deaths in South Africa, a figure which is likely to grow as the smoking population ages and suffers the health sequelae of smoking. ${ }^{1}$ Tobacco control efforts in South Africa have achieved some degree of success, reducing the prevalence of smoking in 1993 from $51.4 \%$ among men and $12.9 \%$ among women to $43.8 \%$ among men and $11.7 \%$ among women, respectively, in $2000 .^{2}$ These reductions have been mainly attributed to sharp increases in cigarette prices between 1993 and 2000. ${ }^{3}$ Although smoking rates in South Africa have declined, cessation rates have remained low. ${ }^{2}$ To increase cessation rates, more people should attempt to quit smoking, and succeed to do so.

Factors associated with successful attempts to quit among Americans included older age, higher education level, married or living with a partner, non-Hispanic white, fewer lifetime attempts to quit, not switching to low-tar/nicotine products, not having others smoke at home, and a No Smoking policy at work. ${ }^{4}$ A very high prevalence of smoking in alcoholdependent populations was also demonstrated in the USA, suggesting that this vulnerable population may require focused interventions for smoking cessation. Although alcohol abuse remains high in South Africa, ${ }^{6}$ limited data are available on the relationship between alcohol abuse and smoking in South Africa.

Most reports on the factors that relate to smoking cessation are based on data from developed countries. Since smoking and alcohol abuse are associated with social disadvantage, and

Department of Community Dentistry and School of Health Systems and Public Health, University of Pretoria

Olalekan A Ayo-Yusuf, BDS, MSc, MPH, PhD

School of Health Systems and Public Health, University of Pretoria Ben Szymanski, MPH

Corresponding author: O Ayo-Yusuf (lekan.ayoyusuf@up.ac.za) believe smoking is harmful, have been dependent on alcohol in the past, live in smoke-free homes, or smoke $>20$ cigarettes per day. Similar factors were associated with successful quitting, except that race was not a determinant of success, and those with $1-7$ years' schooling (compared with no education or higher education) were most likely to succeed, while those currently dependent on alcohol were least likely to succeed.

Conclusions. Clinical interventions, programmes targeting alcohol-dependent smokers, and policies that will boost the number of smoke-free homes and increase knowledge about the adverse health effects of smoking, may increase the rate of smoking cessation in South Africa.

S Afr Med J 2010; 100: 175-179. as addressing social disparities in health is an emerging public health priority globally, we sought to determine the sociodemographic correlates of successful cessation attempts among South Africans, and to examine the role of the co-morbidity of smoking and alcohol abuse and, particularly, the effects of problem drinking on attempting, and succeeding, to quit smoking.

\section{Methods}

We used data from the 1998 South African Demographic and Health Survey (SADHS), the largest nationally representative survey available to date, which contains the most comprehensive data on smoking history among South Africans who have ever smoked. The survey contains data collected from 13826 households on health-related matters, including tobacco and alcohol use. Data collection procedures have been published. ${ }^{6,7}$ Our study was restricted to participants who were $\geq 18$ years old ( $N=12481$ ). Participants who reported that they had made a recent successful attempt to quit smoking are compared with those whose attempt was unsuccessful. To compare our data with previously published data, ${ }^{4}$ we defined a quitter as a person who reported smoking at least 100 cigarettes in his or her lifetime, and who reported smoking 'not at all' at the time of the survey. Participants were further refined into recent quitters (stopped smoking within the past 6 months); successful quitters (stopped smoking between 6 months and 10 years previously) and past successful quitters (stopped smoking more than 10 years ago).

Participants who quit less than 6 months ago were excluded because of the known high risk of relapse during this period. Those who quit more than 10 years ago were excluded because of the probability that current survey responses might not reflect their status at the time of the quit attempt and might be subject to greater recall bias. An unsuccessful quitter was defined as a person who reported smoking at least 100 cigarettes in his or her lifetime, had attempted to quit at some point, but at the time of the study was still smoking 'daily' or 
'occasionally'. Those who gave inconsistent responses were excluded from the final analysis (Fig. 1).

Participants with a drinking problem were defined as those who answered Yes to 2 or more of the 4 CAGE questions $^{8}$ (Have you ever felt that you should cut down on your drinking?; Have people annoyed you by criticising your drinking?; Have you ever felt bad or guilty about your drinking?; Have you ever had a drink first thing in the morning to steady your nerves or get rid of a hangover?). A positive CAGE ( $\geq 2$ affirmative replies) have a sensitivity of $100 \%$ and a specificity of $78 \%$ for alcohol dependence in a South African population. ${ }^{9}$ Therefore, for the current study, participants were divided into 4 categories: never drinkers, past dependents (past alcohol dependents i.e. former drinkers), current dependents (alcohol dependents who currently drink), and non-dependents (people who have ever drunk alcohol but who are not dependent).

Social and demographic characteristics such as age, ethnicity, gender, education, urban or non-urban residence, age at which the subject first smoked regularly, whether or not co-residents smoked, whether or not co-workers smoked, and whether or not the subject believed, or was not sure, that smoking harms one's health, were also collected. As in other local studies, ${ }^{6,7}$ an asset index was calculated based on Yes (coded as 1) or No (coded as 0 ) responses to questions about ownership of a radio, $\mathrm{TV}$, telephone, refrigerator, personal computer and washing machine. Each respondent's total index score was ranked to derive three socio-economic groups (high, middle and low), which were used in the analysis.

\section{Statistical analysis}

Because of the complex sampling design used in the SADHS, statistical analysis was done using the complex sample option

\begin{tabular}{|c|c|}
\hline $\begin{array}{l}\text { Have you ever smoked tobacco, } \\
\text { used snuff or chewed tobacco? }\end{array}$ & $\begin{array}{l}\text { No }(N=7548) \text { i.e. never } \\
\text { a tobacco user }\end{array}$ \\
\hline$\downarrow$ & \\
\hline \multirow{3}{*}{$\begin{array}{l}\text { Yes }(N=4933) \\
\text { Have you ever smoked at least } 100 \\
\text { cigarettes ( } 5 \text { packets of } 20 \\
\text { cigarettes) or the equivalent } \\
\text { amount of tobacco in your } \\
\text { lifetime? }\end{array}$} & \\
\hline & $\begin{array}{l}\text { No } \\
\text { Non-smokers }(N=1279)\end{array}$ \\
\hline & Exclusive snuffers $(N=300)$ \\
\hline 7 & \\
\hline \multirow{2}{*}{$\begin{array}{l}\text { Yes }(N=3354 \text { ever smokers }) \\
\text { Have you ever tried to quit } \\
\text { smoking? }\end{array}$} & \multirow{4}{*}{$\begin{array}{l}\text { No }(N=1076) \\
\text { Continuous smokers } \\
\text { Missing=55 }\end{array}$} \\
\hline & \\
\hline & \\
\hline$\downarrow$ & \\
\hline \multirow{2}{*}{$\begin{array}{l}\text { Yes ( } N=2223 \text { quit attempters). } \\
\text { Do you now smoke daily, } \\
\text { occasionally, or not at all? }\end{array}$} & \multirow{2}{*}{$\begin{array}{l}\text { Daily or occasionally ( } N=1652 \\
\text { Unsuccessful quitter }\end{array}$} \\
\hline & \\
\hline \multicolumn{2}{|l|}{$\downarrow$} \\
\hline \multirow{2}{*}{$\begin{array}{l}\text { Not at all ( } N=571 \text { quitters }) \\
\text { How long has it been since you } \\
\text { last smoked daily? }\end{array}$} & \multirow{5}{*}{$\begin{array}{l}<6 \text { months }(N=77) \\
\text { Very recent quitter } \\
\text { or } \\
>10 \text { years }(N=13) \\
\text { Past successful quitter } \\
\text { (inconsistent with response } \\
\text { as nondaily smoker=247) } \\
\text { [excluded from analysis] }\end{array}$} \\
\hline & \\
\hline$\downarrow$ & \\
\hline 6 months -10 years $(N=244)$ & \\
\hline Successful quitters & \\
\hline
\end{tabular}

Fig. 1. Classification of study participants aged $\geq 18$ years $(\mathrm{N}=12481)$ by smoking status. in SPSS version 13.0. Successful and unsuccessful quitters were compared using independent sample $t$-tests for continuous variables, and a chi-square test for categorical variables. A multiple logistic regression was used to predict quitting status, with the main independent variables of socio-economic status and alcohol use, while controlling for other factors that the literature has reported to be associated with quitting ${ }^{4}$ and for which information was available in the 1998 SADHS. A backward selection method was used, starting with the full model of covariates that had significant values in the bivariate analysis, and removing terms with significance levels $>0.1$. Similar comparisons were made between those who attempted to quit and continuous smokers. For all analyses, the level of significance was set at $p<0.05$.

\section{Results}

The 1998 SADHS survey concluded that $61.5 \%$ of South Africans aged $\geq 18$ had never used tobacco. An additional 10.3\% $(N=1279)$ of that sample had smoked, but $<100$ cigarettes in their lifetime. Excluding snuff users who never smoked, this left $28.2 \%$ aged $\geq 18$ years as 'ever smokers' ( $N=3354)$. Of these, $68.1 \%$ ( $N=2223)(95 \%$ confidence interval (CI) 65.9 - 70.4) attempted to quit smoking at some point. Excluding those with inconsistent responses and those whose cessation attempts had been made $<6$ months ago at the time of the survey (owing to the high probability of a relapse), only $14.1 \%$ of those who had ever attempted to quit smoking had succeeded. Therefore, slightly more than $85 \%$ of those who had attempted to quit were unsuccessful.

Groups with an above-average (68.1\%) frequency of cessation attempts included the following characteristics: female, Asian/Indian, white, secondary or higher education, living in smoke-free homes, highest socio-economic status (SES), belief that smoking is harmful, smoked $>10$ cigarettes per day, and reporting a past dependence on alcohol (Table I). Table I also shows the proportion of those who attempted to quit in each category and those who succeeded, according to a bivariate analysis. The highest frequencies of successful quitters were among those $\geq 55$ years old, female, white, reported initiating regular smoking before the age of 14 , lived in a smoke-free home, had 1 - 7 years' schooling, highest SES, believed that smoking was harmful, smoked $>10$ cigarettes per day, and reported a past dependence on alcohol.

After controlling for potential confounders, the final multivariable adjusted logistic regression models for cessation attempts and cessation success found common significant predictors of cessation activity (Table II). Those aged 25 - 34 years, and who smoked hand-rolled cigarettes (as opposed to factory-made cigarettes) were significantly less likely to have attempted to quit. The highest probability for attempting to quit was indicated by being female, white, tertiary education, living in a smoke-free home, highest SES, belief that smoking is harmful, and dependent on alcohol in the past. Increased cessation success was, however, no longer associated with ethnicity or SES, but remained significantly associated with being female, older adult, smoked a high number of cigarettes per day, a smoke-free home, recognised that cigarettes cause harm, and had been dependent on alcohol in the past. Being in the 18 - 25 or 35 - 44 age group, currently dependent on 


\section{Original Articles}

Table I. Characteristics of smokers attempting to quit $(N=2223)$ and those who succeeded in quitting $(N=244)$

\begin{tabular}{|c|c|c|c|c|}
\hline Characteristic & $\begin{array}{l}\text { Cessation attempt } \\
\%(N)\end{array}$ & $p$-value & $\begin{array}{l}\text { Successful quitters } \\
\%(N)\end{array}$ & $p$-value \\
\hline Age & & 0.27 & & $<0.001$ \\
\hline $18-24$ & $66.3(245)$ & & $6.4(16)$ & \\
\hline $25-34$ & $66.2(482)$ & & $13.1(57)$ & \\
\hline $35-44$ & $67.2(538)$ & & $11.1(44)$ & \\
\hline $45-54$ & $68.0(416)$ & & $17.0(50)$ & \\
\hline $55-64$ & $71.1(284)$ & & $23.1(48)$ & \\
\hline$>65$ & $73.4(258)$ & & $19.4(29)$ & \\
\hline Gender & & $<0.001$ & & 0.02 \\
\hline Male & $65.9(1544)$ & & $12.7(158)$ & \\
\hline Female & $73.6(679)$ & & $17.2(86)$ & \\
\hline Race & & $<0.001$ & & 0.04 \\
\hline Black & $67.0(1204)$ & & $12.7(131)$ & \\
\hline Coloured & $58.3(511)$ & & $13.2(47)$ & \\
\hline Asian/Indian & $68.8(92)$ & & $12.2(9)$ & \\
\hline White & $82.9(408)$ & & $20.2(56)$ & \\
\hline Education & & $<0.001$ & & 0.33 \\
\hline None & $60.6(301)$ & & $11.0(27)$ & \\
\hline Primary & $63.7(647)$ & & $16.5(85)$ & \\
\hline Secondary & $70.1(1057)$ & & $13.6(112)$ & \\
\hline Tertiary & $84.0(201)$ & & $13.6(19)$ & \\
\hline Age started regular smoking & & 0.05 & & 0.08 \\
\hline$\leq 14$ & $69.3(224)$ & & $15.8(24)$ & \\
\hline $15-19$ & $65.7(950)$ & & $11.1(84)$ & \\
\hline$\geq 20$ & $70.2(1032)$ & & $13.7(128)$ & \\
\hline Others smoke at work & & 0.56 & & 0.24 \\
\hline Yes & $67.3(735)$ & & $12.3(77)$ & \\
\hline No & $68.4(1479)$ & & $14.7(163)$ & \\
\hline Others smoke at home & & $<0.001$ & & $<0.001$ \\
\hline Yes & $64.3(974)$ & & $9.2(76)$ & \\
\hline No & $71.3(1247)$ & & $18.3(168)$ & \\
\hline Asset index & & $<0.001$ & & 0.01 \\
\hline Low & $61.5(443)$ & & $11.4(44)$ & \\
\hline Middle & $63.2(853)$ & & $10.9(79)$ & \\
\hline High & $75.8(922)$ & & $18.0(120)$ & \\
\hline Location & & 0.18 & & 0.27 \\
\hline Urban & $69.1(1435)$ & & 14.7 (159) & \\
\hline Rural & $66.1(788)$ & & $12.6(85)$ & \\
\hline Belief that smoking harmful & & $<0.001$ & & $<0.001$ \\
\hline Yes & $72.1(1987)$ & & $15.4(234)$ & \\
\hline No & $46.0(230)$ & & $4.5(10)$ & \\
\hline Cigarettes per day (CPD) & & $<0.001$ & & $<0.001$ \\
\hline $1-10$ & $65.2(1523)$ & & $11.5(143)$ & \\
\hline $11-20$ & $72.6(492)$ & & $19.0(66)$ & \\
\hline$\geq 21$ & $78.8(178)$ & & $25.3(33)$ & \\
\hline Smoke own-rolled cigarettes & & $<0.001$ & & $<0.01$ \\
\hline Yes & $57.5(395)$ & & $8.8(32)$ & \\
\hline No & $70.8(1806)$ & & $15.2(210)$ & \\
\hline Alcohol dependence & & $<0.01$ & & $<0.001$ \\
\hline Current dependent & $67.6(662)$ & & $6.5(39)$ & \\
\hline Past dependent & $78.8(274)$ & & $25.0(50)$ & \\
\hline Non-dependent & $67.1(812)$ & & $16.2(99)$ & \\
\hline Never drink & $65.8(473)$ & & $16.4(56)$ & \\
\hline
\end{tabular}

alcohol, and having started regular smoking between age $15-19$, decreased the probability of successful cessation. In attempting to quit, those with 1 - 7 years of schooling, compared with those with no education or higher education, were more likely to succeed (Table II).

Many participants who claimed to have quit smoking, but also responded as currently smoking occasionally (i.e. gave inconsistent responses), were excluded from the analysis on quitting success (Fig. 1). However, sensitivity analysis that included this category of respondents in the category of unsuccessful quit attempts did not change the findings.

\section{Discussion}

Our study characterises, for the first time, South African smokers' quitting activities, and particularly in relation to alcohol abuse. Subjects who were categorised as being alcohol-dependent but who indicated that they had stopped consuming alcohol were twice as likely to have attempted 


\section{Original Articles}

\begin{tabular}{|c|c|c|}
\hline Characteristic & $\begin{array}{l}\text { Cessation attempt } \\
\text { Odds ratio }(95 \% \mathrm{CI})\end{array}$ & $\begin{array}{l}\text { Successfully quit } \\
\text { Odds ratio }(95 \% \mathrm{CI})\end{array}$ \\
\hline \multicolumn{3}{|l|}{ Gender } \\
\hline Male & 1 & 1 \\
\hline Female & $1.60(1.27-2.04)$ & $1.48(1.02-2.15)$ \\
\hline \multicolumn{3}{|l|}{ Race } \\
\hline Black & $0.90(0.62-1.29)$ & NS \\
\hline Coloured & $0.49(0.34-0.69)$ & \\
\hline Asian/Indian & $0.61(0.38-0.99)$ & \\
\hline White & 1 & \\
\hline \multicolumn{3}{|l|}{ Education } \\
\hline None & 1 & 1 \\
\hline Primary & $1.29(0.92-1.59)$ & $1.86(1.06-3.26)$ \\
\hline Secondary & $1.37(1.02-1.85)$ & $1.32(0.73-2.40)$ \\
\hline Tertiary & $2.42(1.44-4.04)$ & $1.46(0.66-3.25)$ \\
\hline \multicolumn{3}{|l|}{ Others smoke at home } \\
\hline No & $1.33(1.10-1.61)$ & $2.57(1.83-3.60)$ \\
\hline Yes & 1 & 1 \\
\hline \multicolumn{3}{|l|}{ Asset index } \\
\hline Low & 1 & \\
\hline Middle & $1.04(0.80-1.35)$ & \\
\hline High & $1.48(1.07-2.06)$ & NS \\
\hline \multicolumn{3}{|c|}{ Belief that smoking harmful } \\
\hline Yes & $2.59(2.04-3.29)$ & $5.17(2.12-12.60)$ \\
\hline No & 1 & 1 \\
\hline \multicolumn{3}{|c|}{ Smoke own-rolled cigarettes } \\
\hline Yes & $0.78(0.62-0.99)$ & NS \\
\hline No & 1 & \\
\hline \multicolumn{3}{|c|}{ Age started regular smoking } \\
\hline$\leq 14$ & 1 & 1 \\
\hline $15-19$ & $0.80(0.59-1.08)$ & $0.51(0.28-0.93)$ \\
\hline$\geq 20$ & $0.94(0.68-1.30)$ & $0.70(0.38-1.26)$ \\
\hline \multicolumn{3}{|c|}{ Cigarettes per day (CPD) } \\
\hline $1-10$ & 1 & 1 \\
\hline $11-20$ & $1.21(0.95-1.53)$ & $1.87(1.30-2.70)$ \\
\hline$\geq 21$ & $1.50(1.01-2.24)$ & $2.63(1.55-4.47)$ \\
\hline \multicolumn{3}{|l|}{ Alcohol dependence } \\
\hline Current dependent & $1.27(0.99-1.63)$ & $0.43(0.26-0.72)$ \\
\hline Past dependent & $2.11(1.52-2.94)$ & $2.04(1.29-3.22)$ \\
\hline Non-dependent & $0.94(0.74-1.20)$ & $1.04(0.69-1.56)$ \\
\hline Never a drinker & 1 & 1 \\
\hline
\end{tabular}

to quit smoking and were twice as likely to have succeeded, compared with those who never drank or were non-dependent. Although smokers who were currently alcohol-dependent were more likely to attempt to quit smoking, they were much less likely to be successful; this indicates the difficulty of quitting smoking when there is current dependence on nicotine and alcohol - a finding consistent with other studies. ${ }^{3}$ The reduced probability of successfully quitting smoking by alcoholics who smoke, together with the greater risk of cancer among this group of smokers, highlights the need for focused intervention for alcohol-dependent smokers seeking assistance to quit smoking.

During 1998, females were more likely to make an attempt to quit smoking and to succeed. Reports ${ }^{2,10}$ showing that, unlike for men, there has not been a decline in smoking prevalence among women, therefore suggest an increase in commencing smoking among women at a rate higher than at which older female smokers have been quitting.
Our findings about other socio-demographic variables associated with cessation are similar to those demonstrated in the USA's population. ${ }^{4}$ In both studies, living in a smokefree home was one of the strongest predictors of success in attempting to quit smoking. While smoking in the home cannot be regulated by law, increased public education campaigns could influence smokers to voluntarily stop smoking in the home. ${ }^{11}$

Smoke-free workplaces were found to be significant predictors of cessation success in the USA ${ }^{4}$ but not in South Africa, which may be due to differences in the enforcement of smoking bans in public settings and workplaces. Indeed, recent data suggest that, despite the introduction of the ban on public smoking in 2001, ${ }^{12}$ the general prevalence of smoking has not declined significantly from the figures obtained in $1998 .{ }^{10} \mathrm{In}$ 2008, South Africa amended the Tobacco Control Act of 1993 to increase significantly the fines for violating smoking bans. ${ }^{13} \mathrm{It}$ remains to be seen what effect, if any, this amendment has on cessation rates. 
Increased education, which was significant in cessation attempts but not cessation success in South Africa, was significant for cessation success in the USA. However, those with $1-7$ years of education were more likely to succeed in quitting than those without education, which may reflect the effect of the high cost of cigarettes relative to income with, possibly, somewhat more knowledge of the harm of smoking, than among those who have not attended school at all. This finding is consistent with a report suggesting that South Africans of lower SES were more sensitive to cigarette price increases. ${ }^{2}$ Considering the low price of loose cigarette tobacco, it was not surprising that those who smoked hand-rolled cigarettes were also less likely to attempt to quit than those who smoked the more expensive factory-made cigarettes.

We found perception of harm to be a very strong predictor of success in quitting. While relatively few South Africans remain unaware that smoking is dangerous, those who are unaware of that fact or who do not believe that smoking is harmful, are less likely to attempt to quit; and when they attempt to do so, they are less likely to be successful. South Africa's ethnic and linguistic diversity has a potential influence on ethnic differences in the level of awareness of current text warnings, which are only in English. ${ }^{14}$ The implementation of graphic visual warning labels as envisaged in the newly amended Tobacco Control Act ${ }^{13}$ could prove beneficial in communicating the harmful effects of smoking to less educated smokers in South Africa.

In our study, smoking more than 20 cigarettes per day was a significant predictor of cessation attempts and cessation success. The finding that smoking a higher number of cigarettes per day is associated with increased cessation success corroborates findings in the USA. ${ }^{15}$ However, the latter findings differ from other reports which suggest that lighter smokers have higher cessation success compared with heavier smokers. Nevertheless, it is conceivable that heavier smokers may be more motivated to quit, as they are more likely to have experienced smoking-related adverse health conditions, whereas light smokers might feel less motivation to quit because of a perceived lower personal risk.

Our findings suggest that special attention be paid to patients who are dependent on both nicotine and alcohol, as it may be more difficult for them to quit smoking than for other smokers. From a policy perspective, this means that treatment centres should be organised to treat co-dependence and to improve strategies to increase public awareness that 'light smoking' ( $<10$ cigarettes per day) is not harmless. Effective smoking cessation programmes may need to involve family members who may also be smokers.

\section{Limitations}

This study is subject to limitations. The dataset dates from 1998 but is the largest and most complete available for South Africa, and was uniquely able to examine the factors distinguishing between the decision to attempt to quit, and successful quitting. Other researchers have also utilised such large, but similarly dated, datasets in providing an understanding of smoking cessation correlates in the USA., ${ }^{4,15}$ Furthermore, recent data on smoking rates in South Africa have shown no significant change since $1998,{ }^{10}$ consequently, our findings remain relevant today. Nevertheless, to the extent that the implementation of the ban on smoking in public settings between the survey period and the present may have a differential effect on the different socio-demographic groups' motivation to quit, additional studies on smoking cessation correlates are needed.

Another limitation is the cross-sectional nature of the original survey. This temporal ambiguity leads to the possibility of reverse causation of the observed effects. Smoking and drinking habits were assessed by self-report only, and are therefore subject to reporting and/or recall bias.

Despite these limitations, this paper provides crucial characteristics of the South African population who smoke and attempt to quit smoking. It potentially informs future public policy and guides clinical practice for promoting smoking cessation.

Data were obtained with permission from the South African National Department of Health (DoH) through the South African Data Archives (SADA) hosted at the South African National Research Foundation (NRF). The SADHS survey was funded by the DoH under the co-ordination of the Medical Research Council of South Africa. The preparation of this manuscript was supported by a UICC American Cancer Society Beginning Investigators fellowship funded by the National Cancer Institute (NCI, USA).

\section{References}

. Groenewald P, Vos T, Norman R. et al. Estimating the burden of disease attributable to smoking in South Africa in 2000. S Afr Med J 2007; 97: 674-681.

2. Van Walbeek C. Recent trends in smoking prevalence in South Africa - some evidence from AMPS Data. S Afr Med J 2002; 92: 468-472.

3. Heffner JL, Barrett SW, Anthenelli RM. Predicting alcohol misusers' readiness and ability to quit smoking: a critical review. Alcohol Alcohol 2007; 42: 186-195.

4. Lee C, Kahende J. Factors associated with successful smoking cessation in United States, 2000. Am J Public Health 2007; 97: 1503-1509.

5. Littleton J, Barron S, Prendergast M, Nixon SJ. Smoking kills (alcoholics)! Shouldn't we do something about it? Alcohol Alcohol 2007; 42: 167-173.

6. Parry CD, Plüddemann A, Steyn K, Bradshaw D, Norman R, Laubscher R. Alcohol use in South Africa: findings from the first Demographic and Health Survey (1998). I Stud Alcohol 2005; 66: 91-97.

7. Steyn K, Bradshaw D, Norman R, et al. Tobacco use in South Africans during 1998: the first Demographic and Health Survey. J Cardiovasc Risk 2002; 9: 161-170.

8. Mayfield D, McLeod G, Hall P. The CAGE Questionnaire: Validation of a new alcoholism screening instrument. Am J Psychiatry 1974; 131: 1121-1123.

9. Claassen JN. The benefits of the CAGE as a screening tool for alcoholism in a closed rural Claassen JN. The benefits of the CAGE as a screening too
South African community. SAfr Med J 1999; 89: 976-979.

10. Peer N, Bradshaw D, Laubscher R, Steyn K. Trends in adult tobacco use from two South African demographic and health surveys conducted in 1998 and 2003. S Afr Med J 2009; 99: 744-749.

11. Levy DT, Friend KB. The effects of clean indoor air laws: what do we know and what do we need to know? Health Educ Res 2003; 18: 592-609.

12. Republic of South Africa. Tobacco Products Control Amendment Act, 1999 (Act No 12 of 1999). Government Gazette, No. 19962. Pretoria: Government Printers, 1999.

3. Republic of South Africa. Tobacco Products Control Amendment Act, 2007 (Act No 23 of 2007). Government Gazette No 30821. Pretoria: Government Printers, 2008.

14. Reddy P, Meyer-Weitz A, Levin, J. South Africans' Response to Tobacco Control Health Warnings. Cape Town: Medical Research Council, 1996.

15. Levy DT, Romano E, Mumford E. The relationship of smoking cessation to sociodemographic characteristics, smoking intensity, and tobacco control policies. Nicotine Tob Res 2005; 7: 387396.

Accepted 9 December 2009. 